\title{
Learning physical examination skills outside timetabled training sessions: what happens and why?
}

\author{
Robbert J. Duvivier · Koos van Geel • Jan van Dalen • \\ Albert J. J. A. Scherpbier • Cees P. M. van der Vleuten
}

Received: 23 December 2010/ Accepted: 16 June 2011/Published online: 28 June 2011

(C) The Author(s) 2011. This article is published with open access at Springerlink.com

\begin{abstract}
Lack of published studies on students' practice behaviour of physical examination skills outside timetabled training sessions inspired this study into what activities medical students undertake to improve their skills and factors influencing this. Six focus groups of a total of 52 students from Years 1-3 using a pre-established interview guide. Interviews were recorded, transcribed and analyzed using qualitative methods. The interview guide was based on questionnaire results; overall response rate for Years 1-3 was $90 \%(n=875)$. Students report a variety of activities to improve their physical examination skills. On average, students devote $20 \%$ of self-study time to skill training with Year 1 students practising significantly more than Year 3 students. Practice patterns shift from just-in-time learning to a longitudinal selfdirected approach. Factors influencing this change are assessment methods and simulated/real patients. Learning resources used include textbooks, examination guidelines, scientific articles, the Internet, videos/DVDs and scoring forms from previous OSCEs. Practising skills on fellow students happens at university rooms or at home. Also family and friends were mentioned to help. Simulated/ real patients stimulated students to practise of physical examination skills, initially causing confusion and anxiety about skill performance but leading to increased feelings of competence. Difficult or enjoyable skills stimulate students to practise. The strategies students adopt to master physical examination skills outside timetabled training sessions are
\end{abstract}

R. J. Duvivier $(\bowtie) \cdot$ J. van Dalen

Skillslab, Faculty of Health Medicine and Life Sciences, Maastricht University, P. O. Box 616, 6200, MD, Maastricht, The Netherlands

e-mail: r.duvivier@maastrichtuniversity.nl

K. van Geel

Student, Faculty of Health Medicine and Life Sciences, Maastricht University, Maastricht, The Netherlands

A. J. J. A. Scherpbier

Institute for Medical Education, Faculty of Health, Medicine and Life Sciences, Maastricht University, Maastricht, The Netherlands

C. P. M. van der Vleuten

Department of Educational Development and Research, Faculty of Health Medicine and Life Sciences, Maastricht University, Maastricht, The Netherlands 
self-directed. OSCE assessment does have influence, but learning takes place also when there is no upcoming assessment. Simulated and real patients provide strong incentives to work on skills. Early patient contacts make students feel more prepared for clinical practice.

Keywords Undergraduate - Medical students - Practical P Physical examination skills · Clinical skills

\section{Introduction}

Recent years have seen increasing attention for physical examination skills in the medical curriculum. Pleas from clinicians to restore the art of physical diagnosis as a core competency for students have not gone unheard (Anderson et al. 2001). In recommendations for changes in the content and delivery of the undergraduate medical curriculum, various bodies have emphasised the importance of physical examination skills and recommended essential skills in which students have to demonstrate competence and proficiency before graduation. (General Medical 1993) (Colleges 1998; Metz et al. 2001).

All this attention has encouraged many medical schools to revise their curricula to include clinical skills and to establish clinical skill centres to provide appropriate training. (Du Boulay and Medway 1999; Dent 2001; Stark and Fortune 2003).

There is some disagreement about the scheduling of physical examination skills in the curriculum: in the preclinical (Ledingham 1998; Bradley and Bligh 1999) or in the clinical (Corbett et al. 2008) phase of the undergraduate curriculum. Remmen showed that students in medical schools offering longitudinal skills programmes were better prepared for clinical rotations (Remmen et al. 2001). Others have argued that skills training should be integrated with real life practice (Silverman and Wood 2004), and clinical clerkship directors have indicated that the majority of skills should be learned during clerkships. (O'Brien et al. 2007).

Students appreciate skills training as preparation for future medical practice (Lam et al. 2002). It also appears to ease the transition from the theoretical phase to the clinical phase of undergraduate medical education (Prince et al. 2000a, b).

Students learn skills not only during formal training sessions but also by engaging in a variety of activities either in preparation for or complementary to regular training sessions. The existing evidence about students' preparation for skills training is ambiguous. Most studies found that students prepare for training sessions and practise outside timetabled teaching activities. Rudland et al. recently suggested that students mostly practise skills on each other and rehearse routines (Rudland et al. 2008). However, a study by Mavis revealed that students who practised for more than $3 \mathrm{~h}$ spent only $20 \%$ of that time actually performing skills, while the remaining time was used to review textbooks and class notes. (Mavis 2000) There is anecdotal support for the hypothesis that students' learning and practising outside timetabled sessions is limited. As much as one-third of students never practise outside training sessions. (Bhoopatkar and Weam 2008).

The limited and conflicting evidence regarding students self directed activities in skills training leaves an unsatisfactory gap in our knowledge about skill training. In order to increase our understanding, we pose the following research questions:

- which activities do medical students undertake outside regular training sessions to improve their physical examination skills? 
- how much time do they spend on skill practice, what factors influence their practice behaviour and why?.

This paper will describe a sequential study with focus group interviews based on questionnaire results.

\section{Methods}

\section{Setting}

The study was carried out at Maastricht University. Starting in the 1 year, clinical skills training has a prominent place in the six-year problem-based curriculum. Curriculum content in Years 1-3 is delivered in theme-based, six to ten-week blocks. The skills programme runs in parallel with the blocks and its content is aligned with block content. Approximately 125 formal training contact hours for skills are scheduled. Box 1 provides examples of skills addressed. A training session typically lasts ninety minutes and is conducted in groups of eight to ten students. Students can prepare by studying recommended reading before training sessions. A typical training session consists of a four-stage process comprising demonstration of the skill by the teacher, explanation of the skill by the teacher, supervised practice (first on models/manikins, then on peers) and corrective critique. (Duvivier 2010a).

Years 4-5 consist of clinical rotations and year 6 consists of an 18-week research internship and an 18-week clinical internship in one clinical department. Skills training in these years is mainly focused on refreshing and rehearsing skills, because the essential clinical skills have been addressed during the previous years. The skills training programme is developed, organised and delivered by the Skillslab, a specialised educational facility (Van Dalen 1997).

During the first 3 years students take part in a communication skills programme, consisting of simulated patient encounters and group sessions, in which students provide feedback on the recorded encounters of their peers. Simulated patients are primarily used for teaching communications skills; when students are required to take a physical examination during simulated patient encounters they will have received formal training in the

Box 1 Examples of physical examination skills taught in years $1-3$
Examination of foot/ankle (distorsion)

Auscultation of the lungs

Central venous pressure, Peripheral arterial circulation and blood

Pressure measurement

Percussion and palpation of the abdomen

Cranial nerves

Tumor palpation

Pediatric abdominal examination

Neurological examination

Taking cervical smear test

Examination in pregnancy, normal labour and delivery

Motor development infant

Examination of the (Painful) shoulder

Andrological and urological examination 
Skillslab beforehand. (Duvivier 2010b)In Year 3, students have real patient encounters on 1 day per week in the community (general practice) or the university hospital. The patient contacts serve as the starting point for self-study and group discussions, as described in detail elsewhere. (Diemers et al. 2007) Students sit in on consultations, and gradually take on more responsibilities such as history taking and physical examination.

At the end of years 1, 3 and 5 there is a compulsory Objective Structured Clinical Examination (OSCE) Performance is scored on checklists by trained observers. Passing the OSCE is prerequisite for advancing to the next stage of the curriculum.

\section{Sequential study design}

We used a sequential study approach with focus groups interviews guided by questionnaire results. This method allows for a broad and possibly superficial collection of themes (statistical analysis of quantitative data) as well as in-depth exploration of experiences (using qualitative focus groups).

The questionnaire asked about the amount of time devoted to skill practice and about learning resources used. The results were used to identify important factors to be pursued during the focus group interviews.

\section{Questionnaire}

We developed a questionnaire based on the literature and on expert opinions. After piloting among four students (2nd and 3rd Year) and review by four medical education experts (all professors and holding PhDs), some modifications were made. The final questionnaire consisted of thirteen questions and took $10 \mathrm{~min}$ to complete. It consisted of two parts: questions about age, sex and year of study, and questions about the amount of time devoted to studying and skill practice (current year only) See appendix 1 for the full questionnaire. Before completing the questionnaire, the participating students received an explanation of the purpose of the questionnaire. Students participated voluntarily and received no compensation.

We approached all students in Years 1-3, because after the 3 year students no longer attend scheduled skill training sessions. Not all students could be reached: 875 out of 972 completed the questionnaire giving an overall response rate of $90 \%$. The sample comprised 298 first-year students ( $92 \%$ of the Year 1 cohort), 292 s-year students (87\% of the Year 2 cohort) and 285 third-year students (90\% of that cohort). The data of 45 students who failed to state their year of training were not used in the analysis that considered year of study as a variable.

SPSS Software (version 15.0 for MS Windows) was used to analyse the questionnaire data. We calculated mean scores, standard deviations, and performed t-tests to determine significant differences. A $p$ value $<0.05$ was considered significant.

\section{Focus groups}

We used a qualitative approach for in-depth exploration of students' skill training activities, because it can elicit a wide variety of opinions and includes multiple perspectives. We organised focus group interviews in accordance with guidelines described by Morgan. (Morgan 1997) We used an interview scheme based on the results of the questionnaire. It contained general open questions and prompting questions to be asked when elaboration of 
a topic did not occur spontaneously. See appendix. Recruitment was done via an e-mail sent to all students of Years 1-3 explaining the purpose and procedure of the study and inviting the students to participate, followed by a reminder e-mail 2 weeks later. Our aim was to collect data until saturation had been reached. We randomly interviewed 52 students (12 male, 40 female) from the total that had responded. We randomly assigned participants to two groups per study year: six groups in total. The participants received a small financial compensation for participating in the study. The participants did not significantly differ in terms of study results from the general student population. Gender distribution was significantly different: $64 \%$ of questionnaire respondents were female while $77 \%$ of focus group participants were female.

Twelve sessions in total (two per group, two groups per study year 1-3) were held and facilitated by one researcher (AJJAS or JvD). A second researcher (KvG) observed and took notes, interrupting to ask additional questions, if necessary. First sessions lasted 60-70 min. During the second session (20-30 min) the findings of the first session were verified and clarified. The sessions were recorded and transcribed literally. Participants were allowed to review the transcribed sessions and make additions (member check). The transcripts were independently analysed by three researchers (RJD, KvG, JvD). Comments were coded and analyzed for emerging themes.

Two of the researchers (RJD and $\mathrm{KvG}$ ) were medical students. In order to prevent bias (due to preconceptions and experiences that might affect data collection and analysis) we adopted an iterative analytical process. The central approach of the analysis was constant comparison: issues of interest in the data were compared for similarities and differences. The researchers discussed the process afterwards and reached consensus on any inconsistencies (Strauss and Corbin 1990).

At the time of study, educational research studies reporting students' opinions did not require approval from the ethics committee at Maastricht University. However, relevant ethical issues were carefully considered by the Department of Educational Research and Development.

\section{Results}

We present the results of the quantitative analysis of the questionnaire data, followed by the themes that emerged from the qualitative analysis of the focus group transcripts, with illustrative quotes.

The results are grouped under two categories and several subheadings, providing answers to the questions: how do students practise physical examination skills outside training sessions and what influences these activities?

How do students practise physical examination skills?

The mean age of the respondents was 20.3 years $(S D=1.50$ years) and $64 \%$ were female. This reflects the overall age and gender distribution in the medical student population of Maastricht University.

Time spent practising skills outside timetabled training sessions

Students reported an average of $17 \mathrm{~h}$ (SD 6.3) per week for self-directed study and $3.4 \mathrm{~h}$ (SD 2.2) for clinical skills practice outside timetabled training sessions. So $20 \%$ of time for 
self study was devoted to skills. Students in Year 3 reported a significantly lower number of hours for clinical skills than their first-year counterparts (2.9 vs. $3.5 \mathrm{~h})$ (Table 1).

\section{Learning resources}

The focus group sessions revealed six categories of resources used by the participants: textbooks, examination guidelines, scientific articles, the Internet, videos/DVDs and scoring forms from previous OSCEs.

Videos (supplied by the university either online or in the library) were considered superior to photographic material, as they showed the actual sequence of the steps being demonstrated. Videos on websites like YouTube were rarely used, mainly due to doubts concerning their accuracy. Some students mentioned using Wikipedia, especially to get a quick overview of a problem/subject.

I watched the DVDs quite a lot. You read the guidelines but you are not quite sure what exactly it is you are supposed to do and it is very good to actually see what you have to do. I think there is real added value to that (year 2, group 2, student 3 ). Those DVDs are quite helpful: it is easier than reading about it and you see someone demonstrating the skills. Year2, group 2, student 5).

General textbooks were not frequently used by Year 1 students. Students in Year 3 reported using them to link complaint, disease and physical examination. Some students said they only studied the guidelines and never used any other learning resources when practising clinical skills.

Students said they used the scoring forms from previous OSCEs to get an idea of what to expect in the OSCE and to detect any deficiencies in their skills).

There is so much theory and the question is where to start and then scoring forms are useful, for you do know you have to know all the examinations. But in this way you can see what they are going to ask (year 2, group 2, student 6).

\section{Location}

Students can use university rooms, equipped with all the necessary materials to practise physical examination skills. Some students said they had never used these rooms. As inhibiting factors they mentioned suboptimal materials or outdated learning resources and having to reserve the room in advance, which they considered cumbersome and inflexible.

Most students said they preferred practising in the comfort of their own homes. They thought it was more enjoyable, with all materials (books, videos, Internet, notes) handy and without being restricted to resources and opportunities/times offered by the university. One

Table 1 Time spent on study-related activities

\begin{tabular}{|c|c|c|c|c|}
\hline & Year 1 & Year 2 & Year 3 & Total \\
\hline $\begin{array}{l}\text { Mean number of } \\
\text { hours of self study } \\
\text { per week }\end{array}$ & $\begin{array}{l}15.6 \mathrm{~h}(\mathrm{SD} 6.3) \\
68 \% \text { of total } \\
\text { study time }\end{array}$ & $\begin{array}{c}16.4 \mathrm{~h} \text { (SD 6.4) } \\
71 \% \text { of total } \\
\text { study time }\end{array}$ & $\begin{array}{c}15.8 \mathrm{~h}(\mathrm{SD} 6.2) \\
65 \% \text { of total } \\
\text { study time }\end{array}$ & $\begin{array}{c}17.0 \mathrm{~h} \text { (SD 6.3) } \\
72 \% \text { of total } \\
\text { study time }\end{array}$ \\
\hline $\begin{array}{l}\text { Mean number of } \\
\text { hours per week for } \\
\text { skills }\end{array}$ & $\begin{array}{c}3.5 \mathrm{~h}(\mathrm{SD} 2.3) \\
22 \% \text { of self } \\
\text { study time }\end{array}$ & $\begin{array}{l}3.7 \mathrm{~h}(\mathrm{SD} 2.4) \\
23 \% \text { of self } \\
\text { study time }\end{array}$ & $\begin{array}{c}2.9 \mathrm{~h}(\mathrm{SD} 1.8) \\
18 \% \text { of self } \\
\text { study time }\end{array}$ & $\begin{array}{c}3.4 \mathrm{~h}(\mathrm{SD} 2.2) \\
20 \% \text { of self } \\
\text { study time }\end{array}$ \\
\hline
\end{tabular}


disadvantage of practising at home was potential distractions, mostly the risk of socialising instead of practising. Some students saw this as an advantage though, especially with more intimate examinations, as it takes away some of the anxiety surrounding them, such as undressing in front of a group of peers.

It is nicer to be in your underwear with just two girlfriends and to just chat around a bit. (year 2, group 1, student 4 [female student]).

Aids

Students said they practised physical examination skills on: family, fellow students, housemates. The pros and cons of each group were discussed. Using lay people (family, housemates, friends) forces students to be very precise in choosing their words and in demonstrating an examination. They used more medical jargon and explained less when they were practising with fellow students. Some students said they instructed their fellow students to pay particular attention to this pitfall, but commented that it did not always work out as a result of unconscious socialisation.

My friend is a 2 year medical student and it is really easy to practise with him for he can tell me like 'you're doing this the wrong way, you're doing that the wrong way', when I practise with my mother, she is thinking 'oh, you are doing really well, you are just like a real doctor', but she cannot tell me when I get it wrong (year 1, group 2, student 3).

\section{Fellow students}

The main advantage of practising with fellow students is that they can give feedback. Some students mentioned practising with housemates or friends who were senior medical students to get the most useful advice. Peer students were appreciated for their ability to think along when practising and to challenge established patterns. Many students reported feeling uncertain when they were practising without a teacher present. They wished to have more opportunities to practise at the university with an expert available for questions and feedback.

If you get it wrong there is nobody there to tell you, so you never know if you are getting it right and that is quite frustrating (year 2, group 2, student 4).

You may practise abdominal examination but when you do percussion the wrong way there is nobody there to tell you that that's not how it is done (year 3, group 1, student 6).

Students also valued the opportunity to be examined and to feel the effect of certain procedures: too hard, too soft etc.

One student explicitly mentioned practising with a variety of different people in order to get an idea of the differences between real patients.

I sometimes go to my grandmother. She is very old and that makes such a difference. She thinks it's great. She is 90 years old, so when you listen to her lungs you hear almost nothing because it is all very muted. Or my friend's grandmother. They all have lungs. Everybody has to know what I am studying (year 1, group 2, student 5). 


\section{What influences practising?}

\section{Influence of OSCEs}

Responses from 1 year students showed that the uncertainty surrounding the OSCE is a strong incentive to practise physical examination skills. In later years students seemed to have become more familiar with the purpose of the exam, but there was still considerable anxiety about the expected level of competence.

Students acknowledged that they should probably start practising earlier in the year, or more regularly, but they cited lack of time and a limited sense of priority as the main reasons for their peak in practising activities just before the OSCE. Some students suggested more tests, perhaps two OSCEs per year, in order to stimulate them to practise.

The immediate prospect of the OSCE. That you write more down during training.

Really much more, yes (year 1, group 1, student 8).

Influence of simulated and real patients

Simulated patient encounters served as a stimulus to practise for many students, although there was some disagreement about the place of clinical skills other than communication skills in these encounters. Most students considered communication skills more important. Students suggested that better alignment of physical examination skills training sessions with simulated patient encounters would encourage more intensive preparation for the encounters. Students were motivated to prepare for the encounters, as they wanted to give the simulated patient the impression of being professional and well prepared. Some said they also wanted to make a good impression on their peers, who later watch the recorded encounter, although most students said this was not a reason to work on their clinical skills. Students said they would prefer to receive feedback on other skills besides communication, because as things were now, they felt they were just playacting.

In our group no feedback is given about content aspects. So I say to someone with an ankle, well let me feel your ankle, come over here. Sit down please and then I do a fake examination which is wrong in every possible way (year 1, group 2, student 4).

First and second year students thought real patients were too far in the future to be a stimulus to practise right now.

This year I haven't given any thought to real patients not at any moment [when practising skills] But maybe next year I will think more about real patients when I am going to a general practice. (year 2, group 1, student 2).

Third year students have regular patient contacts in hospital and primary care settings. They said these were highly motivating. There were three distinct effects of real patient contacts in the third year with relevance to clinical skills.

1. Real patient contacts stimulate students to practise clinical skills.

2. Real patient contacts cause confusion about "what is the correct way".

3. Real patient contacts lessen the "shock of practice"/make students feel more prepared for the reality of clinical practice.

As for preparation, the third year students described that they practised specific parts of clinical examinations (e.g. special knee tests) focused on the department where they had 
patient contacts. Most students said they prepared and practised for two reasons: (1) the patient and (2) self-confidence. Students want to come across as being competent and in control during the patient encounter. Where students in earlier years mentioned peer pressure and supervisors' expectations as strong incentives for learning, the third year students remarked that the importance of those factors faded when real patients came into play.

In the first 2 years it was only for the test, like I have to start cramming to pass the test and now, in third year, with a patient ... you do not want to be there not knowing how to do a lung examination. (year 3, group 1, student 6).

It is not so much for the supervisor, it is more towards the patient (year 3, group 1, students 4).

It is simply not acceptable to mess around (year 3, group 1, student 7).

It is quite important when you are with a patient that you know what to do and that you are not standing there aimlessly. For me that is the main motivation to prepare really well. (year 3, group 2, student 7).

\section{Influence of clinical environment}

Students described several confusing experiences when they first entered the clinical environment. Overall, students found that the reality of clinical practice in Year 3 was rather shocking because it confronted them with deficiencies in their knowledge and skills. Being confronted with a different culture, an unfamiliar role and novel interaction with healthcare staff also made them feel uncertain.

Time pressure and competing interests were frequently mentioned as having an adverse effect on the quality of clinical skill performance. Students reported that it was difficult to choose the most appropriate skills, because they were used to doing a full physical examination.

And with physical examination you are taught to listen for so long and at so many places and then you are with a GP and he puts his stethoscope at 4 places within $30 \mathrm{~s}$ $\ldots$ it is a matter of more experience as well. (year 3, group 1, students 5).

In addition, students noticed that there was little agreement among clinicians concerning the correct way to perform certain skills. Some students reported negative experiences involving clinicians that openly doubted the validity of techniques that were taught at the university. This caused increased anxiety and confusion. In general, students thought they learned a lot from seeing practising physicians perform. Tips and tricks on efficiency and dexterity were particularly useful for students.

With the abdomen you have a skillslab and you are taught to determine the outline of the liver and we are taught to do that in such a way that you think ... about here, for I know it should be approximately there ... but he showed us a way that works really well. You put your stethoscope here and then you brush with your finger and then you hear the difference where you are brushing, you hear it extremely clearly. It seems strange that we should not learn this in the skillslab ... (year 3, group 1, students 3). 
Students in the final semester of year three reported a subtle shift in how they worked compared to year 1 or 2 . They noticed that they had built a progressively more integrated knowledge base, not just incorporating basic and clinical science knowledge but also physical examination skills.

You know more and more and at a certain point things start to fall into place. Right now I notice this very strongly with skills: you are thinking more and more like I hear this and I hear that and you can make connections [...] and in the first year I just outright memorised lists. (year 3, group 1, student 4).

You integrate different steps of the examination. When you have seen something on inspection, you think during auscultation 'hey I just have to hear that (year 3, group 1, student 5).

This shift, from "how do I do this" to "why am I doing this and what does it mean", was regarded by the students as a very positive confirmation of their growing competence. Although the prospect of clinical rotations was still quite daunting, many students felt well prepared and confident with regard to their physical examination skills. Students expected their experiences in Year 3 would help to ease the transition to clinical training.

In the clinic I never really feel that I might be deficient in examination skills, I think that I am more likely to have deficiencies in knowledge to interpret... I am quite capable of doing a physical examination (year 3, group 2, student 8).

One reported drawback of students' early experiences with the clinical environment is how it affected their preparation for the OSCE. Many students saw the step-by-step approach they were expected to use in the test ("checklist") as an unnatural regression towards the type of thinking they had used in the first 2 years. They argued that they would benefit from a holistic rating procedure that favoured diagnosis-driven thinking over linear thinking (ticking off each box for every small step).

I think it is good that you learn the basics and then move on but I think it is a pity that you have to put on an act for the OSCE.... "It should be done precisely so" and even if the doctor at the exam does things very differently himself but it is not on the scoring form, it has o be done exactly as it is written. You feel as if you are in a play. (year 3, group 1, student 4).

When you do an examination you do it because you have an idea at the back of your head and you want to find something in the patient and then you think of a diagnosis and the observer says that you did not look at the pattern of the hair on the legs in relation to circulation deficiencies. You could not see it because the legs were shaven but when you would have said it would have meant an extra mark. It's just so stupid, things like that I just don't need them (year 3, group 2, students 3).

Influence of the nature of the examination

The students reported a wide variety of study habits with regard to clinical skills.

Two factors in particular appeared to stimulate students to practise:

- Skills that are difficult to perform.

- Skills that are enjoyable to perform. 
Students felt they had to do more practice for skills they considered more difficult than others, such as breast examination. One student reported having paid extra attention to this skill because a relative had been recently diagnosed with breast cancer. Other students said they rehearsed this skill (not by actually practising the skill but by reading up on the procedure), because they were expected to examine their peers and felt this examination was more intimate than others.

I think that unconsciously it plays a role. It is not so much embarrassment but because you feel you have to be able to do it. You do not want to seem backward or something. (year 2, group 1, student 6).

Because you practise on someone and it is quite stressful the first time (year 2, group 2, student 6).

A strong motivator among Year 1 students was the enjoyment they felt in performing certain skills. Auscultation of the heart and lungs was frequently mentioned as being enjoyable to do, as was bandaging. We will discuss additional benefits of this approach later.

What I also do is practising at home on my girlfriend, my father, my mother. Anyone who feels like it comes under the stethoscope (year 3, group 1, student 2).

\section{Discussion}

This study aimed to explore how students work outside scheduled training sessions to improve their physical examination skills, and what factors play a role in this. Using a combination of qualitative and quantitative methods, we discovered that students report a variety of activities to improve their physical examination skills.

On average, students devote $20 \%$ of self-study time to skill training with Year 1 students practising significantly more than Year 3 students. Learning resources used include textbooks, examination guidelines, scientific articles, the Internet, videos/DVDs and scoring forms from previous OSCEs. Student practise skills on fellow students, family members or friends at university rooms or at home.

The motivation to practise is influenced by both external and internal factors. Assessment provides a strong incentive for students to practise, caused by anxiety about the format of the exam and the expected level of competence. Real and simulated patient encounters also motivate students to practise their skills. Students mention patient pressure and supervisors' expectations as drivers for learning. In later years the impact of those external factors gradually fades and is replaced by intrinsic motivation. Students report that practice increases their self-confidence and perceived level of competence.

In conclusion, students' practice patterns shift from just-in-time learning to a longitudinal self-directed approach during the first three years of the curriculum. Factors influencing this change are A) assessment methods and B) authenticity of the learning environment by introducing simulated/real patients.

These outcomes are in line with other research on the transition from preclinical to clinical training (Prince et al. 2000a, b; Prince et al. 2004; Diemers et al. 2008). However, the current study is the first to address the acquisition of physical examination skills and the strategies students adopt to master these. We will consider theoretical explanations for the reported findings, and discuss possible implications for medical education. 


\section{Influence of assessment methods}

The influence of OSCEs on students' practising behaviour provides partial support for the conventional assertion that assessment drives learning. (Muijtjens et al. 1998; McLachlan 2006) However, our results also reveal significant incentives for learning that are not related to assessment. The OSCE does influence learning strategies, but learning takes place also when there is no upcoming assessment, as is demonstrated by the influence of real patients. This shows that students will work on their physical examination skills, even when they do not know if and when they will be formally assessed. Intrinsic motivation to practise for (simulated) patient encounters is high. We therefore propose to modify the maxim "assessment drives learning" to include "and patients drive practising" within the context of physical examination skills. The influence of early patient contacts on learning physical examination skills extends the growing body of evidence on patient-based education into the skills domain. (Dornan et al. 2006a, b).

Contrary to earlier studies, which investigated time spent preparing for an OSCE (Mavis 2000; Rudland et al. 2008), we found that the larger part of practice time is dedicated to skill performance rather than reviewing textbooks and notes. Students in Year 3 practise less outside timetabled training sessions as they (1) feel increasingly competent and (2) have opportunities to practise on real patients in general practice and hospital settings. A recent study also found that students regularly practised skills on each other outside timetabled training sessions. (Rudland et al. 2008) These spontaneous, self-directed group learning activities seemed to be inspired by a PBL-environment. This cooperative/collaborative learning may be seen as a manifestation of the 'hidden curriculum' (Snyder 1971) and as such warrants more research.

\section{Authenticity of the learning environment}

The reported shift towards clinically oriented thinking was addressed in earlier studies on knowledge acquisition in the theoretical curriculum. (Diemers et al. 2008; Vanhell et al. 2008) Our findings complement the theory that students progressively integrate their knowledge and skills while problem-solving. Cognitive psychological theories of clinical reasoning have emphasised that the structure of knowledge differs in experts (clinicians) and novices (medical students) (Schmidt and Boshuizen 1993). As expertise develops and medical students acquire extensive clinical experience, they develop the ability to recognize and manage symptoms efficiently and effectively. Our findings suggest that early introduction of skills training contributes to the development of competence and confidence in physical examination skill performance. Remmen et al. demonstrated earlier that longitudinal skills training is more effective than clerkships to learn physical examination skills (Remmen et al. 2001).

Early exposure to physical examination skills would therefore assist students in developing an extensive cognitive database of possible clinical findings as preparation for clerkship rotations. During their clerkships this database will develop further. Seeing patients in clinical care will spur the development of 'illness scripts', cognitive structures that clinicians use for storing and organizing information about patient symptoms and conditions in memory (Feltovich and Barrows 1984). Illness scripts contain not only clinically relevant information about patient cases, but also the context in which the case was seen. In everyday practice, the resulting 'pattern recognition' allows relevant information to be retrieved efficiently thereby contributing to a doctor's ability at differential diagnosis (Eva 2005). 
In this model, based on cognitive psychological research, the more opportunities students have to see patients or to be exposed to clinical material, the richer their database of illness scripts will be. This will provide more opportunity to organise schemes of relevant information in memory readily available for quick retrieval when needed (Schmidt et al. 1990).

Consequently, including clinical scenarios or (simulated) patients in physical examination skills teaching will assist the development of clinical competence.

Physical examination skills are demonstrably an important part of the diagnostic process (Sackett 1992). There is evidence that diagnostic accuracy improves with training and time spent on a task (Patel and Groen 1991). Exposing medical students to a large number of clinical cases improves their performance (Vosti et al. 1997; Papa et al. 1999), especially when combined with quality feedback (Papa et al. 1999).

Although feedback during performance is important, research in skills acquisition has shown that humans learn best if feedback is incorporated in training designs (Fischman and Oxendine 1998). Students in our study emphasised the motivational effect that (simulated) patients have on their practising behaviour, but they felt that feedback on their physical examination skills was sometimes lacking. Evidence shows that individual feedback and remedial instruction in general improve learning outcomes (Bloom et al. 1987). Provision of feedback immediately after summative tests has been associated with improved competence (Newble and Jaeger 1983).

In addition to the large body of literature on feedback in general, several studies have described feedback during physical examination skills training (Wigton et al. 1986; Dunnington et al. 1992; Tape et al. 1992; Schwind et al. 2001). The learning effect is boosted when feedback is specific, for example when teachers highlight which aspects of physical examination skills are redundant in reaching a correct diagnosis, or when teachers point out areas where more work is needed. Those examples were deduced from research on preclinical teaching, but evidence suggests that the underlying principles would also be valid in the clinical learning environment (Johnson and Carpenter 1986).

One of the central themes emerging in our study was the motivational effect (simulated) patients have on students. Next to the resulting drive-to-practise this has on students, additional benefits can be bolstered with literature.

The transition to the clinical phase of undergraduate medical education has often been described as a stressful period (Prince et al. 2000a, b). Students experience stress due to increased working hours, uncertainty as to what is expected of them and self-perceived lack of knowledge (Godefrooij et al. 2010).

Boshuizen described how the resulting 'shock of practice' is associated with a temporary decrease in students' ability to properly use biomedical knowledge in clinical reasoning (Boshuizen 1996). Students in our study described similar confusing experiences during their first patient contacts. However, in contrast to the literature on the "shock of practice" these first patient contacts took place before the clerkship phase. Our findings suggest that early patient contacts in physical examination skills teaching may improve students' preparedness for clinical clerkships.

Recent research adds more evidence to the value of early patient contacts in overcoming the 'shock of practice' (Littlewood et al. 2005; Dornan et al. 2006a, b; Diemers et al. 2008; Yardley et al. 2010).

Learning physical examination skills in a longitudinal integrated skills programme could facilitate a student's ability to perform those skills in the 'real world': the clinical workplace (Remmen et al. 2001). Our findings suggest that students feel well-prepared to do so and show that students use the skills learned when examining (simulated) patients. 
When learning in one situation (the preclinical skills programme) enhances performance in another situation (the clinical workplace), positive transfer has occurred. In contrast, when something learned in one situation (the preclinical skills programme) hinders learning or performance in a second situation (the clinical workplace) then negative transfer has occurred (Ormrod 2004).

Examples of both positive and negative transfer are discussed in our study. Factors contributing to positive transfer are the increasing complexity of skills and using (simulated) patients as authentic stimuli for learning. Conditions adding to negative transfer include socialisation processes, uncertainty about what is expected and conflicting techniques being used in practice.

The implications of our findings for medical education are fourfold.

Firstly, considerations for skills teachers. Our findings show that students in later years are capable of identifying areas that need work, especially when they are confronted with real patients. Students can create learning opportunities to address their shortcomings. Skills teachers could accommodate this process by using a student-centred approach, empowering students to take an active role in their learning (Martens 2009).

Secondly, considerations with regard to the learning environment. Educators should note that authentic learning environments stimulate students to learn physical examination skills. Bringing the real world into the classroom (using simulated or real patients) or taking the classroom to the real world (using outpatient departments to practise) can contribute greatly to the learning of skills. Experiential learning should be considered as an educational strategy for physical examination skills. (Kolb 1984).

Thirdly, considerations for course constructors and the curriculum at large. Building on the considerations for the learning environment, the statements from our students emphasised the importance of alignment of training sessions with (simulated) patient encounters. Curriculum alignment includes both the place of skills training in a course and the arrangement of skills training with communication sessions. Course constructors should safeguard the longitudinal integration of physical examination skills training in the curriculum.

Fourthly, considerations for assessment procedures. Examiners should be aware that students tailor their learning to what they are tested on, and adjust assessment accordingly. This strategy, also called 'measurement-driven instruction' can have powerful educational consequences. (Popham 1987; Vleuten 1996; Rust 2002). One such adjustment might be to revise current OSCE models, and abandon the checklist approach in favour of a more clinically oriented test which allows for variation in thinking. (Hodges et al. 1999) Such a test puts different requirements on examiners, and this has implications for staff training.

The limitations of this study are that we relied on students' self-reports and thereby on their perceptions. Another limitation is that the confidence or lack of confidence of the students in their own abilities is not known and this would influence their perception of their learning of clinical skills. It should also be taken into account that the students who accepted the invitation to participate in our study might be the most enthusiastic ones. Even though saturation was reached in all focus groups and all groups discussed similar themes, it cannot be ruled out that NOT all themes were appropriately covered. Nevertheless, we think self-reporting is a strength too, since the impact of various influences on practising behaviour will be mediated through self-perceptions. Another strength is our sequential approach, combining self-reporting by questionnaire and focus groups. The high response rate on the questionnaire and the iterative procedure adopted for the qualitative analysis assure representativeness of our findings. The translation of our findings to other curriculum structures needs further clarification. 
This exploratory study has indicated areas for further study: the introduction of early patient contacts, clinical reasoning in undergraduate years, innovative assessment of clinical skills. Further research should also explore if and how self-reported study behaviours are related to performance in clinical situations and achievement on formal assessments.

Open Access This article is distributed under the terms of the Creative Commons Attribution Noncommercial License which permits any noncommercial use, distribution, and reproduction in any medium, provided the original author(s) and source are credited.

\section{References}

Anderson, R. C., Fagan, M. J., et al. (2001). Teaching students the art and science of physical diagnosis. The American Journal of Medicine, 110(5), 419-423.

Bhoopatkar, H., \& Weam, A. (2008). Medical students describe their patterns of practising clinical examination skills outside time tabled sessions. Medical Teacher, 30(3), 334.

Bloom, B., Madaus, G., et al. (1987). Evaluation to improve learning. McGraw-Hill: New York.

Boshuizen, H. (1996). The shock of practice: Effects on clinical reasoning.

Bradley, P., \& Bligh, J. (1999). One year's experience with a clinical skills resource centre. Medical Education, 33(2), 114-120.

Colleges', A. O. A. M. (1998). Report 1:Learning objectives for medical student education. Guidelines for medical schools. Washington: Medical School Objectives Project.

Corbett, E. C., Jr, Elnicki, D. M., et al. (2008). When should students learn essential physical examination skills? views of internal medicine clerkship directors in North America. Academic Medicine, 83(1), 96.

Dent, J. A. (2001). Current trends and future implications in the developing role of clinical skills centres. Medical Teacher, 23(5), 483-489.

Diemers, A. D., Dolmans, D., et al. (2007). Students' perceptions of early patient encounters in a PBL curriculum: A first evaluation of the Maastricht experience. Medical Teacher, 29(2-3), 135-142.

Diemers, A. D., Dolmans, D., et al. (2008). Students opinions about the effects of preclinical patient contacts on their learning. Advances in Health Sciences Education, 13(5), 633-647.

Dornan, T., Littlewood, S., et al. (2006a). How can experience in clinical and community settings contribute to early medical education? A BEME systematic review. Med Teach, 28(1), 3-18.

Dornan, T., Littlewood, S., et al. (2006b). How can experience in clinical and community settings contribute to early medical education? A BEME systematic review\#. Medical Teacher, 28(1), 3-18.

Du Boulay, C., \& Medway, C. (1999). The clinical skills resource: A review of current practice. Medical Education Oxford, 33, 185-191.

Dunnington, G., Reisner, E., et al. (1992). Teaching and evaluation of physical examination skills on the surgical clerkship. Teach Learn Med, 4(2), 110-114.

Duvivier, R. J., Dalen J. van, Bartholomeus, P., Scherpbier, A. J. J. A., \& Verwijnen, G. M. (2010a). Skills training. In H. Van Berkel, A. J. J. A. Scherpbier, H. H. Hillen, \& C. P. M. Van der Vleuten (Eds.), Lessons from problem based learning. Oxford University Press.

Duvivier, R. J., Rethans, J. J., \& Dalen J. van. (2010b). Communication skills training. In H. Van Berkel, A. J. J. A. Scherpbier, H. H. Hillen, \& C. P. M. Van der Vleuten (Eds.), Lessons from problem based learning. Oxford University Press.

Eva, K. W. (2005). What every teacher needs to know about clinical reasoning. Medical Education, 39(1), 98-106.

Feltovich, P., \& Barrows, H. (1984). Issues of generality in medical problem solving. Tutorials in problembased learning: a new direction in teaching the health professions. In H. Schmidt \& M. De Volder (Eds.), Assen, Van Gorcum (pp. 128-142).

Fischman, M., \& Oxendine J. (1998). Motor skill learning for effective coaching and performance. Applied sport.

General Medical, C. (1993). Tomorrow's doctors: Recommendations on undergraduate medical education.

Godefrooij, M. B., Diemers, A. D., et al. (2010). Students' perceptions about the transition to the clinical phase of a medical curriculum with preclinical patient contacts; a focus group study. BMC Med Educ, $10,28$.

Hodges, B., Regehr, G., et al. (1999). OSCE checklists do not capture increasing levels of expertise. Academic Medicine, 74(10), 1129. 
Johnson, J. E., \& Carpenter, J. L. (1986). Medical house staff performance in physical examination. Archives of Internal Medicine, 146(5), 937-941.

Kolb, D. A. (1984). Experiential learning: Experience as the source of learning and development. NJ: Prentice-Hall Englewood Cliffs.

Lam, T. P., Irwin, M., et al. (2002). Early introduction of clinical skills teaching in a medical curriculumfactors affecting students' learning. Medical Education, 36(3), 233-240.

Ledingham, I. M. A. (1998). Twelve tips for setting up a clinical skills training facility. Medical Teacher, 20(6), 503-507.

Littlewood, S., Ypinazar, V., et al. (2005). Early practical experience and the social responsiveness of clinical education: Systematic review. BMJ, 331(7513), 387-391.

Mavis, B. E. (2000). Does studying for an objective structured clinical examination make a difference? Medical Education, 34(10), 808-812.

McLachlan, J. C. (2006). The relationship between assessment and learning. Medical Education, 40(8), 716.

Metz, J. C. M., Verbeek-Weel, A. M. M., et al. (2001). Blueprint 2001: Training of doctors in The Netherlands. Utrecht: NFU.

Morgan, D. L. (1997). Focus groups as qualitative research, Sage pubns.

Muijtjens, A. M. M., Hoogenboom, R. J. I., et al. (1998). Relative or absolute standards in assessing medical knowledge using progress tests. Advances in Health Sciences Education, 3(2), 81-87.

Newble, D. I., \& Jaeger, K. (1983). The effect of assessments and examinations on the learning of medical students. Medical Education, 17(3), 165-171.

O'Brien, B., Cooke, M., et al. (2007). Perceptions and attributions of third-year student struggles in clerkships: do students and clerkship directors agree? Academic Medicine, 82(10), 970.

Ormrod, J. (2004). Human learning. Upper Sadle River: Pearson Education.

Papa, F. J., Aldrich, D., et al. (1999). The effects of immediate online feedback upon diagnostic performance. Academic Medicine, 74(10), S16-S18.

Patel, V. L., \& Groen, G. J. (1991). Developmental accounts of the transition from medical student to doctor: Some problems and suggestions. Medical Education, 25(6), 527-535.

Popham, W. J. (1987). The merits of measurement-driven instruction. Phi Delta Kappan, 68(9), 679-682.

Prince, K., van de Wiel, M., et al. (2000a). A qualitative analysis of the transition from theory to practice in undergraduate training in a PBL-medical school. Advances in Health Sciences Education, 5(2), $105-116$.

Prince, K. J., van de Wiel, M., et al. (2000b). A qualitative analysis of the transition from theory to practice in undergraduate training in a PBL-Medical School. Adv Health Sci Educ Theory Pract, 5(2), 105-116.

Prince, K., van de Wiel, M. W. J., et al. (2004). Junior doctors' opinions about the transition from medical school to clinical practice: A change of environment. Educ Health, 17(3), 323-331.

Remmen, R., Scherpbier, A., et al. (2001). Effectiveness of basic clinical skills training programmes: A cross-sectional comparison of four medical schools. Medical Education, 35(2), 121-128.

Rudland, J., Wilkinson, T., et al. (2008). You can do it late at night or in the morning. You can do it at home, I did it with my flatmate. The educational impact of an OSCE. Medical Teacher, 30(2), 206-211.

Rust, C. (2002). The impact of assessment on student learning: how can the research literature practically help to inform the development of departmental assessment strategies and learner-centred assessment practices? Active learning in higher education, 3(2), 145.

Sackett, D. L. (1992). The rational clinical examination. A primer on the precision and accuracy of the clinical examination. JAMA, 267(19), 2638-2644.

Schmidt, H., \& Boshuizen, H. (1993). On acquiring expertise in medicine. Educational Psychology Review, 5(3), 205-221.

Schmidt, H., Norman, G., et al. (1990). A cognitive perspective on medical expertise: Theory and implication. Academic Medicine, 65(10), 611-621.

Schwind, C. J., Boehler, M. L., et al. (2001). Development of physical examination skills in a third-year surgical clerkship. American Journal of Surgery, 181(4), 338-340.

Silverman, J., \& Wood, D. F. (2004). New approaches to learning clinical skills. Medical Education, 38(10), 1021-1023.

Snyder, B. R. (1971). The hidden curriculum, Knopf New York.

Stark, P., \& Fortune, F. (2003). Teaching clinical skills in developing countries: Are clinical skills centres the answer? Education for Health, 16(3), 298-306.

Strauss, A. L., \& Corbin, J. (1990). Basics of qualitative research: Grounded theory procedures and techniques. CA: Sage Newbury Park.

Tape, T. G., Kripal, J., et al. (1992). Comparing methods of learning clinical prediction from case simulations. Med Decis Making, 12(3), 213-221.

Van Dalen, J. (1997) Skillslab: Centre for training of skills. Maastricht University, Maastricht; (3rd Ed.). 
vanhell, E., Kuks, J., et al. (2008). Transition to clinical training: Influence of pre-clinical knowledge and skills, and consequences for clinical performance. Medical Education Oxford, 42(8), 830-837.

Vleuten, C. P. M. (1996). The assessment of professional competence: Developments, research and practical implications. Advances in Health Sciences Education, 1(1), 41-67.

Vosti, K. L., Bloch, D. A., et al. (1997). The relationship of clinical knowledge to months of clinical training among medical students. Academic Medicine, 72(4), 305-307.

Wigton, R. S., Patil, K. D., et al. (1986). The effect of feedback in learning clinical diagnosis. Journal of Medical Education, 61(10), 816-822.

Yardley, S., Littlewood, S., et al. (2010). What has changed in the evidence for early experience? Update of a BEME systematic review. Med Teach, 32(9), 740-746. 